\title{
EDUKASI PENCEGAHAN PENULARAN HIV-AIDS DAN MANAJEMEN STRESS PADA KOMUNITAS IRT DENGAN HIV
}

\author{
Etha Rambung $^{1 *}$, Romauli Nainggolan², Hanna Tabita Hasianna Silitonga ${ }^{3}$ \\ ${ }^{1,3}$ Fakultas Kedokteran Universitas Ciputra Surabaya, UC Town, Citraland, Surabaya, Jawa Timur \\ ${ }^{2}$ Fakultas Managemen Universitas Ciputra Surabaya, UC Town, Citraland, Surabaya, Jawa Timur \\ *Email: etha.rambung@ciputra.ac.id
}

\begin{abstract}
Abstrak
Komunitas Bu'Daya (Ibu berdaya dengan HIV-AIDS) adalah komunitas khusus ibu rumah tangga yang terinfeksi HIV-AIDS di Kecamatan Tandes, Surabaya. Komunitas ini beranggotakan lima orang ibu rumah tangga (IRT) yang berdomisili di sekitar Kecamatan Tandes. Permasalahan yang didapatkan dari hasil diskusi dan observasi dengan mitra adalah masih ada anggota komunitas yang tidak minum obat teratur, memiliki perilaku berisiko penularan HIV-AIDS, dan ketidakmampuan ibu untuk menjelaskan masalahnya kepada anggota komunitas yang lain sehingga ketika ada masalah, cenderung memilih untuk menghilang dan tidak menjalani pengobatan. Setelah menganalisa masalah tersebut dan sharing dengan komunitas, maka solusi yang ditawarkan untuk menyelesaikan permasalahan mitra adalah memberikan pendampingan pengobatan dan penguatan pengetahuan pentingnya minum obat teratur, memberikan pendampingan dan penguatan pencegahan penularan HIV, dan memberikan pedampingan dan pelatihan manajemen stress sehingga mampu menghadapi masalah yang timbul akibat kondisinya. Metode pelaksanaan yang dilakukan adalah pendampingan, penyuluhan, diskusi, dan pelatihan. Hasil kegiatan menunjukkan peningkatan pengetahuan Ibu tentang bahaya putus obat, cara pencegahan penularan, dan cara menghadapi serta menyelesaikan masalah terkait kondisinya serta peningkatan persepsi diri.
\end{abstract}

Kata kunci: Edukasi, HIV-AIDS, ART

\section{Abstract]}

Komunitas Bu'Daya (Strong women with HIV-AIDS) is a special community for housewives infected with HIV-AIDS in Kecamatan Tandes, Surabaya. This community consists of five housewives who live around the Kecamatan Tandes. The problems obtained from the results of discussions and observations with partners are that there are community members who do not take regular medication, have risky behavior for HIV-AIDS transmission, and the mother's inability to explain the problem to other community members so that when there is a problem, they tend to choose to disappear and not undergoing treatment. After analyzing the problem and sharing with the community, the solution offered to solve partner problems is to provide medical assistance and strengthen knowledge of the importance of taking regular medication and strengthen prevention of HIV transmission, and provide stress management assistance and training so that they are able to deal with problems that arise. due to his condition. The implementation method used is mentoring, counseling, and training. The results of the activity showed an increase in mother's knowledge about the dangers of withdrawal, how to prevent transmission, how to deal with and resolve problems related to her condition and increase in self-perception.

Keywords: Education, HIV-AIDS, ART

\section{PENDAHULUAN}

Tujuan keenam pembangunan Milenium (MDGs) adalah memerangi HIV/AIDS, malaria dan penyakit menular lain. Mengurangi separuh angka infeksi melalui pengobatan Anti Retroviral (ARV) merupakan tujuan dari indikator ini. Tingginya persentase penyakit HIV/AIDS yang mencapai $54 \%$, akan diperburuk dengan ketidakpatuhan terapi ARV (Anasari \& Yuli Trisnawati, 2018).

Peningkatan jumlah kasus HIV pada ibu rumah tangga dari tahun ke tahun semakin bertambah, bahkan menduduki peringkat kedua pada bulan September 2012 (Larasaty, Shaluhiyah, \& Suryoputro, 2015). Ibu-ibu penderita HIV menghadapi masalah stigma 
sosial baik dari keluarga sendiri maupun dari masyarakat sehingga tidak mempunyai teman berbagi saat ada masalah, mengucilkan diri dan tidak berani terbuka kepada keluarga. Hal ini membuat ibu-ibu rentan putus obat dan melakukan perilaku beresiko penularan (Ardani \& Handayani, 2017).

Komunitas Bu'Daya (Ibu Berdaya) adalah komunitas khusus ibu rumah tangga yang terinfeksi HIV-AIDS di Kecamatan Tandes, Surabaya. Komunitas ini beranggotakan lima orang ibu rumah tangga (IRT) yang berdomisili di sekitar Kecamatan Tandes. Koordinator komunitas ini adalah Ibu Siti Chomariah. Ibu Siti pada awalnya adalah ibu rumah tangga biasa, yang tertular infeksi HIV-AIDS, akibat perilaku berisiko sang suami. Setelah suami Ibu Siti meninggal, ia diberikan pelatihan oleh sebuah lembaga swadaya masyarakat yang bergerak di bidang HIV-AIDS dan diangkat menjadi staf untuk mendampingi para penderita HIV-AIDS. Pada tahun 2018, Ibu Siti membentuk komunitas Bu'Daya agar ada wadah komunikasi dan dukungan khusus bagi ibu rumah tangga yang terinfeksi HIV-AIDS, karena selama ini kelompok dukungan sebaya yang ada di Puskesmas melayani secara umum untuk semua kelompok populasi, sehingga sulit bagi ibu-ibu untuk terbuka dan mengkomunikasikan kondisi mereka. Komunitas ini biasanya berkumpul di rumah ipar Ibu Siti di Kecamatan Tandes.

Permasalahan utama yang dihadapi mitra adalah masih ada anggota komunitas yang tidak teratur minum obat (lost follow up). Hal ini dikarenakan ibu merasa malu jika ketahuan orang lain saat mengambil obat, dan merasa kesakitan akibat efek samping obat. Permasalahan ini sama dengan penelitian yang dilaporkan Sisyahid (Sisyahid \& Indarjo, 2017). Terapi ARV yang tidak teratur dapat menimbulkan efek negatif yang sangat besar (Pariaribo, Hadisaputro, Widjanarko, \& Sofro, 2017). Hal lainnya adalah ketidakmampuan ibu untuk menjelaskan masalahnya kepada anggota komunitas yang lain sehingga ketika ada masalah, cenderung memilih untuk menghilang dan tidak menjalani pengobatan.

Permasalahan kedua adalah masih ada anggota komunitas yang memiliki perilaku berisiko penularan HIV-AIDS. Perilaku berisiko tersebut antara lain tidak memakai kondom ketika berhubungan dengan pasangan. Hal ini dikarenakan ada ibu yang masih menyembunyikan statusnya dari keluarga, karena takut keluarganya tidak bisa menerimanya. Permasalahan ini sama dengan laporan penelitian Putri (Putri \& Tobing, 2016). Ibu yang tidak bisa terbuka akhirnya tidak berani untuk meminta pasangan memakai pengaman saat berhubungan. Hal ini tidak saja membahayakan bagi ibu tersebut, tetapi juga membahayakan keluarga ibu itu bahkan membahayakan anggota komunitas yang lain. Anggota keluarga ibu tersebut berisiko tertular penyakit yang sama tanpa diketahui.

Permasalahan ketiga adalah terbatasnya kemampuan mitra untuk mengatasi masalah putus obat, mencegah perilaku penularan HIV-AIDS dari sesama anggota komunitas atau IRT lain di luar komunitas, dan ketidakmampuan anggota komunitas untuk memotivasi sesama anggota agar tetap menjalani pengobatan serta melakukan perilaku pencegahan penularan. Hal ini karena para ibu tidak tahu bagaimana cara mendukung satu sama lain. Penyakit kronis dan penyakit terminal menjadi stressor tersendiri bagi penderitanya, namun kemampuan adaptasi untuk mengatasi stress tersebut berbeda-beda pada masing-masing penderita (Hidayanti, 2013). Orang dengan HIV-AIDS (ODHA) membutuhkan kelompok dukungan sebaya (KDS) yang terpercaya, komunikatif, berempati, motivator yang baik, mampu mengkomunikasikan dengan baik apa yang mereka ketahui, mampu menunjukkan empati, mengenali kekuatan pribadi dan menumbuhkan rasa percaya diri. Permasalahan ini sama dengan penelitian yang dilaporkan Kamila (Kamila \& Siwiendrayanti, 2010). Anggota komunitas ini adalah ibu rumah tangga dengan usia produktif dan menjadi tulang punggung keluarga dalam memenuhi kebutuhan hidup sehari-hari. Hal ini sama dengan penelitian yang dilaporkan Lestari (Lestari, Hargono, \& Subarniati, 2014). Kemenkes juga merangkul komunitas ODHA dalam mengatasi masalah HIV (Kemenkes RI, 2019). Kegiatan pengabdian masyrakat ini bertujuan untuk mendukung Ibu-ibu penderita HIV yang tergabung dalam Komunitas Bu'Daya agar mampu menerima kondisinya, mengatasi masalahnya dan rutin mengkonsumsi obat 
sehingga dapat mencegah resiko penularan, baik kepada keluarganya sendiri maupun masyarakat di sekitarnya. Ibu yang rutin mengkonsumsi obat, akan mampu untuk beraktivitas dan menghidupi keluarganya. Ibu yang sehat akan mampu mendampingi anakanaknya untuk bertumbuh dengan sehat sehingga mampu mandiri di masa depan.

\section{METODE PELAKSANAAN}

Kegiatan pengabdian masyarakat ini dilaksanakan tanggal 22 dan 27 Agustus 2020. Strategi pelaksanaan yang digunakan untuk membantu mitra adalah dengan penyuluhan, pelatihan, dan pendampingan.

Tahapan kegiatan yang dilakukan sebagai berikut:

1. Survey lapangan menganalisa masalah dan harapan mitra. Hasil survey menemukan beberapa pokok masalah yang dihadapi mitra, antara lain putus obat, perilaku beresiko penularan dan ketidakmampuan mengelola masalah terkait penyakitnya

2. Tahap persiapan dilakukan dengan menyusun rencana kegiatan solusi masalah. Rencana tersebut dikoordinasikankan dengan mitra untuk menentukan waktu dan tempat pelaksanaan serta koordinator tim.

3. Tahap pelaksanaan di awali dengan pelatihan penggunaan video conference WA dan ZOOM. Terkait kondisi pandemi maka beberapa metode pelaksanaan berubah dari luring menjadi daring. Untuk itu maka ibu-ibu dilatih terlebih dulu untuk menggunakan video confrerence WA dan ZOOM karena beberapa ibu masih belum bisa menggunakan aplikasi tersebut. Pelatihan penggunaan zoom pada tanggal 11 Agustus 2020.

4. Tahap pelaksanaan pelatihan kami berdaya, kami cegah penularan HIVAIDS dan rutin minum obat dilaksanakan pada tanggal 22 Agustus 2020. Pelatihan ini bertujuan agar Ibu-ibu memahami penularan HIV-AIDS dan cara pencegahannya, memahami dampak putus obat HIV-AIDS dan termotivasi untuk mengkonsumsi obat secara rutin Sebelum materi diberikan ibu-ibu diminta mengisi pre test melalui google form. Selanjutnya pelatihan dilakukan dengan presentasi materi dan diskusi kasus. Setelah itu dilanjutkan dengan post test dan sharing kondisi terkini ibu, keteraturan konsumsi obat. Ibu-ibu juga diajak mendiskusikan hambatan yang mereka hadapi dalam mengkonsumsi obat dan mencegah penularan.

5. Tahap pelaksanaan pelatihan aku istimewa aku bisa dilaksanakan pada tanggal 27 Agustus 2020. Pelatihan ini bertujuan agar Ibu-ibu mampu menerima kondisinya dan memiliki motivasi bertahan hidup sehingga mereka mampu menghadapi stigma negatif dan diskriminasi dari keluarga dan masyarakat, mampu melakukan manajemen stress sehingga mampu menghadapi masalah yang timbul akibat kondisinya dan tidak putus obat serta mampu berempati dan menjadi pendukung bagi ibu-ibu penderita HIV lain yang menghadapi masalah untuk tetap survive dan tidak putus obat.. Pelatihan di awali dengan mengisi pretest, dilanjutkan presentasi materi dan diskusi kasus. Ibu-ibu juga diajak mendiskusikan hambatan yang mereka hadapi untuk terbuka terkait kondisi mereka kepada keluarga dan persepsi mereka tentang kualitas hidupnya. Setelah pelatihan diadakan post test untuk mengetahui pemahaman ibu-ibu.

6. Tahap pendampingan dilakukan sepanjang pelaksanaan kegiatan pengabdian masyarakat dari bulan JuniSeptember 2020. Pendampingan dilakukan melalui Whats app grup (WAG). Melalui WAG ibu-ibu bisa menceritakan kondisi dan masalah yang mereka hadapi.

7. Tahap terakhir adalah evaluasi dan tindak lanjut kegiatan penyuluhan bertujuan untuk menilai peningkatan pengetahuan mitra dan respon mereka terhadap kegiatan ini.

\section{HASIL DAN PEMBAHASAN}

Kegiatan pelatihan kami berdaya, kami cegah penularan HIV-AIDS dan rutin minum obat telah berjalan dengan baik melalui zoom. Kegiatan terdiri dari dua sesi. Sesi pertama penyampaian materi pencegahan penularan HIV dan dampak putus obat. Sesi kedua adalah hambatan yang mereka hadapi dalam 
mengkonsumsi obat dan mencegah penularan (Gambar 1).

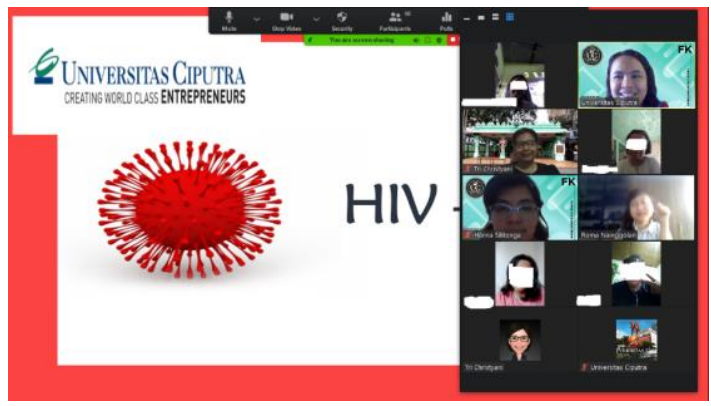

Gambar 1. Pelatihan kami berdaya, kami cegah penularan HIV-AIDS dan rutin minum obat

Hasil pre test dan post test yang dilakukan menunjukkan peningkatan pengetahuan ibu tentang cara pencegahan penularan HIVAIDS dan dampak putus obat. Hasil rata-rata pre test adalah 73, dan meningkat setelah pelatihan (post test) menjadi 92 (Gambar 2). Peningkatan pengetahuan membuat Ibu-ibu dapat rutin minum obat dan selalu aware terkait penularan penyakitnya. Hasil monitoring WAG dalam kurun waktu 2 bulan terakhir tidak ada lagi ibu yang putus obat. Hal ini sejalan dengan penelitian Kurnia yang menunjukkan hubungan antara pengetahuan dengan tingkat kepatuhan terapi ARV, dimana pengetahuan akan memberi pengaruh utama pada kepatuhan terapi penderita ODHA (Kurnia \& Solekhah, 2018).

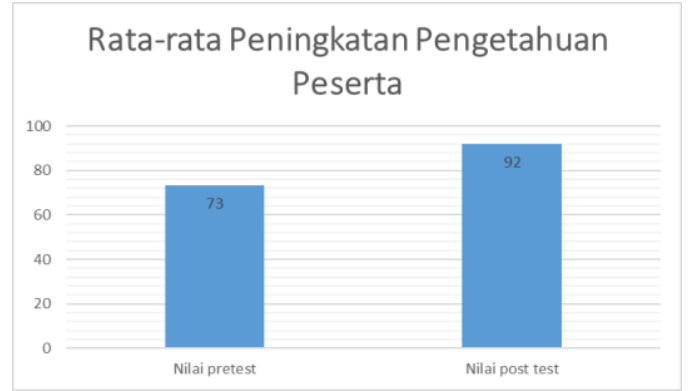

Gambar 2. Grafik peningkatan pengetahuan peserta tentang penularan HIV dan dampak putus obat

Kegiatan pelatihan aku istimewa, aku bisa juga telah berjalan dengan baik melalui zoom (Gambar 3). Hasil pre test dan post test yang dilakukan menunjukkan peningkatan persepsi ibu tentang dirinya. Hasil rata-rata pre test adalah 64, dan meningkat setelah pelatihan (post test) menjadi 89 (Gambar 3). Ibu sangat antusias mendapatkan pelatihan ini dan aktif bertanya. Peningkatan persepsi ini membuat Ibu-ibu dapat menghadapi dengan bijaksana setiap masalah yang timbul terkait penyakitnya dan tetap rutin mengkonsumsi obat, sehingga dapat meningkatkan kualitas hidup Ibu. Hal ini sejalan dengan penelitian Marni, yang menunjukkan hubungan antara tingkat depresi dengan kualitas hidup penderita HIV/AIDS (Marni, Ratnasri, Soares, \& Husna, 2020). Selain itu pelatihan membuat Ibu-ibu menjadi lebih terbuka untuk berbagi masalah yang dihadapi dan saling mendukung diantara komunitas sehingga mereka lenih kuat menghadapi masalah yang ada. Hal ini sejalan dengan penelitian Sari bahwa adanya dukungan sosial dari komunitas dapat memberikan efek positif terhadap kesehatan mental dan membantu menguatkan penderita HIV/AIDS (Sari \& Wardani, 2017).

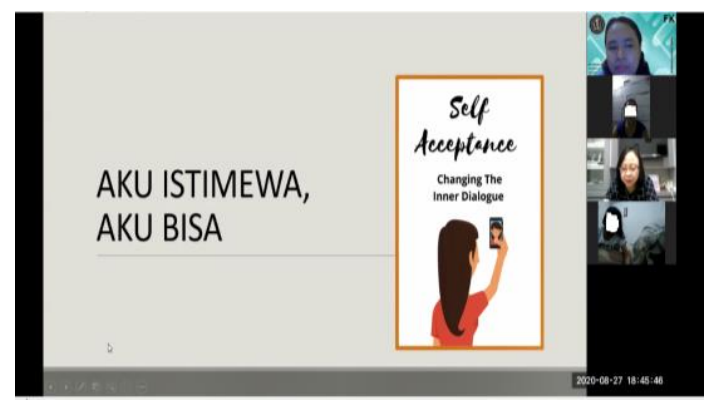

Gambar 3. Pelatihan aku istimewa, aku bisa

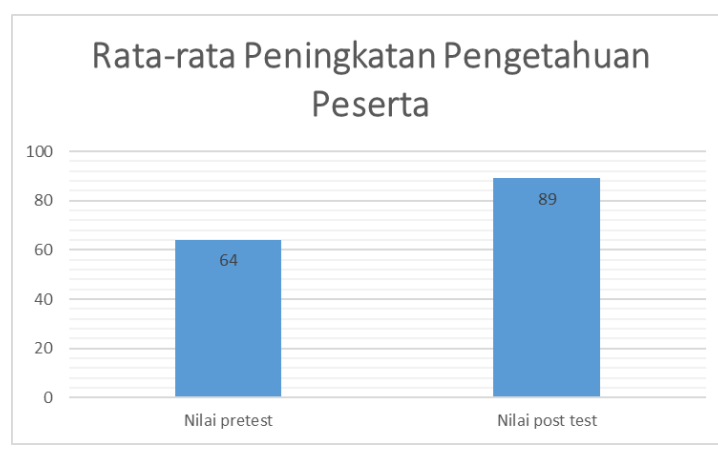

Gambar 4. Grafik peningkatan persepsi peserta tentang dirinya 


\section{KESIMPULAN}

Kegiatan pengabdian masyarakat berjalan lancar dan mitra memberikan respon positif serta antusias mengikuti. Hasil evaluasi kegiatan menunjukkan peningkatan pengetahuan mitra terkait pencegahan HIVAIDS, dampak putus obat dan persepsi diri masing-masing Ibu. Hasil pengabdian juga menolong mitra meningkatkan komunikasi diantara anggota komunitas untuk membangun komunitas pendukung sosial.

\section{REFERENSI}

Anasari, T., \& Yuli Trisnawati. (2018). Hubungan Dukungan Keluarga Dan Pengetahuan Dengan Kepatuhan Ibu Hamil Dengan HIV Dalam Mengonsumsi ARV di RSUD Prof. MArgono Soekarjo Purwokerto. Jurnal Publikasi Kebidanan, 9(1), 100-113.

Ardani, I., \& Handayani, S. (2017). Stigma terhadap Orang dengan HIV/AIDS (ODHA) sebagai Hambatan Pencarian Pengobatan: Studi Kasus pada Pecandu Narkoba Suntik di Jakarta. Buletin Penelitian Kesehatan, 45(2), 81-88. https://doi.org/10.22435/bpk.v45i2.6042 $.81-88$

Hidayanti, E. (2013). Strategi coping stress perempuan dengan HIV/AIDS. Sawwa: Jurnal Studi Gender, 9(1), 89-106.

Kamila, N., \& Siwiendrayanti, A. (2010). Persepsi Orang Dengan Hiv Dan Aids Terhadap Peran Kelompok Dukungan Sebaya. Jurnal Kesehatan Masyarakat, 6(1), 36-43. https://doi.org/10.15294/kemas.v6i1.175 0

Kemenkes RI. (2019). Kemenkes Fokus Temukan Penderita HIV untuk Diobati. 17 Juli. Retrieved from https://www.kemkes.go.id/article/view/1 9071900001/kemenkes-fokus-temukanpenderita-hiv-untuk-diobati.html

Kurnia, D. A., \& Solekhah, U. (2018). Hubungan Pengetahuan HIV/AIDs, Terapi Antiretroviral, dan Infeksi Oportunistik Terhadap Kepatuhan ODHA dalam Menjalani Terapi Antiretroviral. Faletehan Health Journal, $\quad 5(2), \quad 84-89$. https://doi.org/10.33746/fhj.v5i2.13

Larasaty, N. D., Shaluhiyah, Z., \&
Suryoputro, A. (2015). Bentuk-Bentuk Dukungan Keluarga Terhadap Ibu dengan HIV Positif dalam Kepatuhan Terapi ARV di Kota Semarang. Jurnal Promosi Kesehatan Indonesia, 10(2), 116-130. https://doi.org/10.14710/jpki.10.2.116130

Lestari, D., Hargono, R., \& Subarniati, R. (2014). Pengembangan Program Pemberdayaan Peningkatan Kemandirian Ibu Rumah Tangga Pengidap HIV (Studi Kasus pada Komunitas Women Empowerment (WE) Surabaya) Developing Empowerment Program to Enhancing Independency of Housewives with HIV (Case Study on Women Empow. Buletin Penelitian Sistem Kesehatan, 16(3 Jul). https://doi.org/10.22435/bpsk.v16i3Jul.3 466

Marni, M., Ratnasri, N. Y., Soares, D., \& Husna, P. H. (2020). Tingkat Depresi dan Kualitas Hidup Penderita HIV/AIDS di Kelompok Dukungan Sebaya Gajah Mungkur Wonogiri Marni. Jurnal Penelitian Kesehatan Suara Forikes, 11(3), 402-406.

Pariaribo, K., Hadisaputro, S., Widjanarko, B., \& Sofro, M. A. U. (2017). Faktor Risiko yang Mempengaruhi Kepatuhaan Terapi Antiretroviral (ARV) pada Pasien HIV/AIDS di RSUD Abepura Jayapura. Jurnal Epidemiologi Kesehatan Komunitas, 2(1), 7. https://doi.org/10.14710/j.e.k.k.v2i1.396 6

Putri, I. A. K., \& Tobing, D. H. (2016). Gambaran Penerimaan Diri Pada Perempuan Bali Pengidap HIV-AIDS. Jurnal Psikologi Udayana, 3(9), 395406.

Sari, Y. K., \& Wardani, I. Y. (2017). Dukungan Sosial Dan Tingkat Stres Orang Dengan Hiv/Aids. Jurnal Keperawatan Indonesia, 20(2), 85-93. https://doi.org/10.7454/jki.v20i2.361

Sisyahid, A. K., \& Indarjo, S. (2017). Health Belief Model dan Kaitannya dengan Ketidakpatuhan Terapi Antiretroviral Pada Orang dengan HIV/AIDS. Unnes Journal of Public Health, 6(41). 